\title{
Introduction: Dissecting the Greek Debt Crisis
}

\author{
Georgios Karyotis and Roman Gerodimos
}

In 2007, the global financial markets were hit by a 'black swan event', an event so unlikely to occur that it surprised policy makers as much as most economists (Taleb, 2007). The bursting of the housing bubble in the United States (US) and its domino effect on global financial institutions after years of deregulation contributed to a rapid decline in international trade, credit availability and market confidence (Levchenko, Lewis and Tesar, 2010). Global economic imbalances, growing inequality and excessive liberalisation of the financial sector, as well as weaknesses in aggregate demand in both the US and Europe that had previously been disguised by weak regulation and low interest rates were among the underlying problems (Wolf, 2014). The result was the 2008-2012 global recession, the likes of which had not been predicted or seen since the Great Depression of the 1930s. Its intensity and symptoms varied cross-nationally, but for many countries involved a slowing down of their economic activity, an inability to finance budget deficits, and huge social costs in terms of rising unemployment and relative deprivation levels.

In the eurozone, the global economic downturn manifested in 'three interlocking crises' (see Shambaugh, 2012). First, there was a banking crisis, with major Euro-area banks experiencing a capital shortfall, as well as liquidity and solvency problems. Second, there was a sovereign debt crisis, with a number of Central and Eastern European countries, but also Greece, Ireland, Italy, Portugal and Spain facing rising bond yields and struggling to independently repay or refinance pre-existing and mounting government debts. Third, there was a competitiveness crisis, with slowing and unequal growth among eurozone members, which exacerbated the burden on the indebted nations. It soon became apparent that the interconnected and mutually reinforcing 
nature of these three crises would not only undermine the viability of the currency union (Shambaugh, 2012: 157; Eichengreen, 2010) but would also, arguably, produce the greatest challenge the European integration project had faced since the signing of the Maastricht Treaty.

To curtail the development of the multifaceted crisis, the prevailing response and prescription from affected governments and international institutions was the adoption of austerity measures. Rather than an exact recipe, this ensuing 'age of austerity', still ongoing, is characterised by varying degrees (Ladi and Tsarouhas, 2014) and varying combinations of increases or decreases in spending, taxation and benefit entitlements (Melchiorre, 2013). For instance, in countries like France, Spain, Belgium and Slovakia, among others, austerity mainly took the form of increases in taxation, with a parallel increase in some areas of public spending. In most cases, including in Greece, Portugal, Ireland, Italy, Estonia and the United Kingdom, increases in direct and indirect taxation were combined with extensive cuts in government spending and consumption. Whatever the combination of measures, both the economic wisdom of adopting austerity policies (e.g. Corsetti, 2012; Krugman, 2012; Wolf, 2014), as well as their social and political sustainability (e.g. Matsaganis and Leventi, 2014) provoked intense and heated debates, with far-reaching implications that extend beyond Europe and beyond the current crisis.

Greece found itself at the epicentre of this global crisis. Following a decade of fast economic growth (about 4\% on average from 2000-08; see Matsaganis, 2011a) and notable achievements, such as the hosting of the 2004 Olympic Games, Greece was the first and most severely hit member of the eurozone. A number of long-standing structural problems (e.g., see Featherstone and Papadimitriou, 2008), such as its large, outdated and inefficient public sector, widespread corruption and systemic resistance to reforms from organised interest groups (Kalyvas, Pagoulatos and Tsoukas, 2012), had made Greece particularly exposed to the wrath of the global economic downturn. The tipping point and the moment the severity of its sovereign debt problem became evident came in October 2009 , when the newly elected socialist government announced that the earlier reported fiscal data concerning government deficit and sovereign debt had been inaccurate. The projected deficit ratio for 2009 was at that point revised from 3.7\% of its Gross Domestic Product (GDP) - the figure reported to Eurostat in spring 2009 - to $12.5 \%$ of GDP, with its public debt recalculated to $115.1 \%$ of GDP (see EC, 2010a).

Amidst fears of contagion across Europe and rapid increase of spreads on Greek bonds, the Greek government introduced a first package of 
austerity measures in March 2010 and a tax reform in April 2010, which, however, failed to restore market confidence. With involuntary and disorderly default on its debt and exit from the eurozone emerging as real possibilities, in May 2010 the government sought and received an unprecedented $€ 110$ billion loan by the so-called 'troika', consisting of the International Monetary Fund (IMF), the European Central Bank (ECB) and the European Commission (EC). The loan was conditional upon the implementation of extreme austerity measures and regular monitoring, as stipulated in the Memorandum of Understanding (MoU - henceforth 'the Memorandum') that was ratified by the Hellenic Parliament in May 2010 amidst mass protest (Rüdig and Karyotis, 2014). These included radical cuts in salaries and public spending, steep tax increases, privatisations and pension reforms, which collectively were described as 'unexpectedly tough' (Butler, 2010) but were expected to reduce the fiscal deficit below 3\% of GDP by 2014 (IMF, 2010).

When these projections proved unfeasible due, among others, to the depth of its recession and implementation problems (see Stevis and Talley, 2013), Greece and its lenders agreed to a second $€ 130$ billion loan agreement in October 2011. The new programme brought additional austerity measures but also an agreement ('haircut') with private creditors holding Greek government bonds to lower interest rates and accept a 53.5\% face loss. The debt-to-GDP ratio, which had skyrocketed to a forecasted $198 \%$ in 2012 , would be reduced to about $160 \%$, with a targeted gradual decline until it reached a more sustainable level at roughly $120 \%$ of GDP by 2020 . However, the announcement of Prime Minister George Papandreou's intention of holding a referendum on this agreement for the restructuring of Greek debt put it temporarily on hold, resulting in his resignation on 6 November 2011, amidst domestic and European pressures.

These developments paved the way for major political realignment in Greece. A coalition government was formed, supported by the Panhellenic Socialist Movement (PASOK), centre-right New Democracy and the smaller right-wing party LAOS, with Lucas Papademos, the former ECB Vice-President, being appointed as the new Prime Minister. The subsequent May/June 2012 elections saw the formation of a new coalition government, this time under the leadership of New Democracy's Antonis Samaras and with the participation of PASOK and the Democratic Left (DIMAR) party. The Coalition of the Radical Left (SYRIZA) skyrocketed into second place, spearheading the opposition to austerity, while the far-right parties Independent Greeks and Golden 
Dawn entered Parliament for the first time (Karyotis, Rüdig and Judge, 2014). In the months that followed, the fears of a possible Greek exit from the eurozone gradually subsided and Greece appeared to be on the path to fiscal recovery, ending a four-year exile period from market borrowing in April 2014 (see crisis timeline in Appendix). However, the political system remained volatile, with structural and social problems, including high unemployment (26\% in March 2014) and lack of competiveness indicating that the crisis is far from over, not only in Greece but across the eurozone (Wolf, 2014).

With the situation still unfolding, the Greek debt crisis and national and international responses to it continue to polarise opinion, raising complex questions, among others, about the sustainability of the recovery effort and its impact on society and politics. This edited collection aims to deliberate on the origins, management and implications of the Greek crisis, in a comparative context, and in doing so, to generate new theoretical perspectives about the politics of extreme austerity within and beyond Greece.

\section{Key themes and structure}

The literature on the origins, handling and implications of the eurozone and particularly the Greek crises is only starting to extend beyond highly ideological or journalistic accounts (e.g., see Ladi and Tsarouhas, 2014; Saurugger, 2014). The present volume offers a comprehensive coverage of issues relating to austerity politics and the Greek crisis. Drawing on a wealth of unpublished primary data, it identifies tensions, interactions and trade-offs between different actors and aspects of the crisis in a holistic manner. It also seeks to tackle the Greek case not only from a variety of disciplinary perspectives but also in a broader comparative, global even, context of crisis governance in a highly interdependent, globalised era.

The book's point of departure is that crisis management is centrally concerned with exploring answers to the following questions: First, how is the crisis framed and represented in public debates and by whom? Second, what policies are introduced in response and how effective are these in arresting the crisis? Third, what are the implications of these frames and policies for society and politics? Fourth, what are the broader global phenomena driving or affecting both crises and crisis management? To understand austerity politics, it is argued, each of these has to be analysed separately and in relation to each other. This is reflected in the book's structure, developed around four respective themes: the 
framing, the policies, the politics and the comparative analysis of the crisis.

Any crisis typically generates a contest between competing frames concerning its nature and severity, its causes, the responsibility for its occurrence or escalation, and its implications for the future (Entman, 1993). Frames set the parameters and the points of reference for audiences to interpret, categorise and evaluate complex or ambiguous events, such as the eurozone crisis (Benford and Snow, 2000; Druckman, 2001; Boin, 't Hart and McConnell, 2009). Elites manipulate, strategise and fight to have their frame accepted as the dominant narrative (' $\mathrm{t}$ Hart, 1993; Tarrow, 1994; Brandström and Kuipers, 2003; De Vries, 2004; Stone, 2012). These dynamics are explored in the first section of the book, which analyses representations and discourses about the Greek crisis, both domestically and at the European level.

Making some aspects of a crisis more salient in discourse promotes a particular causal interpretation, moral evaluation, and treatment recommendation and is directly linked to the policies introduced in an attempt to master it (Entman, 1993: 52; Scheufele, 1999). Crises do not only have multiple and contested causes but also multiple and contested solutions ('t Hart and Tindall, 2009). The second section of the book assesses the austerity policies implemented in Greece. This includes an evaluation of both the general principles of the bailout agreements negotiated with the IMF, the EU and the ECB, as well as specific policy reforms in key sectors, such as welfare and pensions.

The third section of the book explores the politics of the crisis. The political dimension is centred around the clash between supporters and opponents (both parliamentary and extra-parliamentary) of proposed reforms (Boin, 't Hart and McConnell, 2009). Its focus is principally on analysing the multifaceted consequences of the economic crisis. This includes an assessment of protest and voting behaviour at times of extreme austerity, a discussion of the emotions and behaviours the crisis generates and an analysis of how it is being experienced collectively and individually within the Greek society and polity. Read in conjunction with the previous sections, it is argued that the political ramifications of the crisis are not only dependent on how it is represented and managed but also feed back into these, with the potential to dislocate dominant frames and undermine the successful implementation of policy reforms (also see Lowi, 1972; Pierson, 2006; Boin, 't Hart and McConnell, 2008).

The above framework, expanded in the opening chapter, underlines the symbiotic, cyclical and dynamic relationship between the frames, 
policies and politics of the crisis. This provides the glue for the analyses of substantial chapters in each respective section, which draw on a range of methodological approaches and theoretical literatures, but which collectively form an overarching narrative. The fourth and final section of the book contextualises the Greek case, examining 'the crisis beyond Greece' and offering international perspectives on austerity politics, with chapters on Ireland, Spain, Argentina and Turkey. By juxtaposing case studies and strategies of crisis management, this section highlights common patterns and identifies factors that affect decision-making at both the European and the global level. In sum, this book seeks to offer a pluralistic but coherent account of austerity politics and to explore the perils and limits of crisis management, a question of broader empirical significance and theoretical value. A more detailed overview of the book's contents follows.

\section{Content and contributions}

The book is divided in 14 chapters, spread over its four sections. In the first chapter, Andrew Hindmoor and Allan McConnell provide us with an analytical toolbox, by drawing on the literature on crisis exploitation and management. Their contribution identifies a number of key framing contests around the severity of a crisis, its causes, the motivations of those involved, who or what is to blame, and what policy measures should be put into place in order to restore economic, political and social stability. The chapter then identifies three key crisis management contradictions which are often reflected in bitter debates in the political, social and media arenas. These are the tensions between (i) resolving the crisis vs. protecting the reputation of government, (ii) political parties working together vs. political parties engaging in adversary critique and (iii) solutions which maintain established paradigms and power structures vs. solutions which realign established paradigms and power structures. Hindmoor and McConnell argue that the way in which a society responds to extraordinary crisis episodes is a product of a battleground between multiple and competing power structures, interests and movements, whether seeking to preserve as much as possible of the old order, or to realise visions of a 'new' one.

In Chapter 2, Dimitris Papadimitriou and Sotirios Zartaloudis examine the evolving narratives of key EU actors during the 'bailout' negotiations and unpack the key features of the EU's strategy to contain and resolve the crisis. It is argued that the highly emotive discourse that prevailed during the early stages of the Greek drama, sidetracked 
European policy makers into a strategy that always seemed to produce too little, too late, and neglected key structural defaults of the eurozone's governance regime. Building on a discursive institutionalist perspective, Papadimitriou and Zartaloudis also argue that the peculiarities of the Greek case have served as a 'critical juncture' in the (re)definition of European discourses on solidarity, competitiveness and 'mutual responsibility'. These new discourses have not only conditioned understandings on the causes and appropriate remedies of the 'Greek problem' but have themselves evolved to become a constituent part of a wider identity crisis for the EU, with significant implications for the future trajectory of the European project.

Continuing on the same theme but from the perspective of the Greek media, Chapter 3 by Tereza Capelos and Theofanis Exadaktylos analyses the framing of the crisis in op-ed pieces between 2009 and 2012, focussing on the stereotypical representation of key actors, such as Germany, Greece and the EU. The chapter employs content and discourse analysis, identifying blame attribution frames, which underpin the public's confidence in domestic and European actors and institutions. Capelos and Exadaktylos find that most pieces provided a simplistic and charged account of the crisis, promoting a self-victimising discourse and pointing the finger at government and international elites.

The second section of the book on the policies of extreme austerity begins with a review and evaluation of the first bailout programme adopted in Greece in May 2010. Sotiria Theodoropoulou and Andrew Watt, in Chapter 4, explore the extent to which the Memorandum contained the seeds of its own failure, given the economic context in which it had to be implemented. The chapter analyses the main premises of the adjustment programme in its original form, drawing on the relevant literature in economics and political economy and contrasting these assumptions against what was widely known about Greece at the time. The authors argue that it would have taken a miracle (or several) for the adjustment programme to succeed, even if there had been no obstacles to its implementation. On that basis, it is also argued that the evaluation of the Greek crisis management contains lessons for the handling of other troubled eurozone economies.

In Chapter 5, Platon Tinios analyses what the IMF termed 'a landmark pension reform', the first to pass as a law after the signing of the original bailout agreement. Upon its adoption, pensions were declared safe for a generation. This, however did not prevent pensions in payment to be cut on ten separate occasions between 2010 and early 2013. This chapter explores this apparent paradox by noting that the 2010 reform, passed 
with very little time for preparation, while carrying a heavy legacy of chronic inactivity. It is argued that picking reforms 'off the shelf' with little time to spare and few opportunities of dialogue and reflection, condemned the reforms to be backward-looking and oriented towards problems of the past. As a result, they produced a revamped monolithic state pension system reminiscent of the 1980s rather than a construction appropriate for the 2020s. The lack of preparation indicates that policy makers overlooked the critical role played by the (unreformed) pension system in the propagation of the debt crisis: pensions were a key 'microfoundation of disaster'.

Another important area undergoing policy reform, the welfare state, is studied in Chapter 6. Social solidarity, in Greece more than elsewhere, is channelled through the family and other informal support networks. The functions of social protection are thus supplied by a hybrid welfare system, composed of the formal welfare state but 'shadowed' and supplemented by an informal welfare system based on the family. This symbiosis is frequently noted but its full implications are little appreciated. During the crisis, austerity policies have squeezed the finances of the family, leading to possible 'bankruptcy scenarios', just as greater demands are placed upon it. This chapter by Antigone Lyberaki and Platon Tinios maps the scope of the Informal Welfare State and offers an interpretation for its persistence in Greece. The authors argue firstly, that the hybrid (formal and informal) system of social protection has provided one of the drivers of the current crisis in state finances; and secondly, that the way the social and political consequences are unfolding cannot be seen independently of the complex relationships between the formal and informal welfare systems.

The third section on the politics of extreme austerity begins with Chapter 7, where Georgios Karyotis and Wolfgang Rüdig explore public attitudes to austerity and analyse patterns of protest and voting behaviour, drawing on original panel data. Findings suggest that while a relative majority of Greeks on the onset of the crisis found the austerity measures to be necessary, virtually all agreed that they were also unfair, with about one in four participating in anti-austerity demonstrations. The chapter proceeds to analyse the profile of demonstrators and map the electoral impact of austerity by discussing voting trends from 2009 to 2014. It is suggested that the degree of persuasiveness of competing political narratives plays an important role in averting or encouraging protest, a finding that also tentatively applies to vote choices, which is mainly characterised by a strong anti-incumbent effect. 
The eighth chapter by Sappho Xenakis and Leonidas Cheliotis analyses the issue of crime during the crisis, which, despite its significance within the domestic political arena, has received comparatively little scholarly attention. On the one hand, public anger against traditional mainstream political parties for their handling of the economy and adoption of austerity measures has been further inflamed by concerns about criminality, in the form of both elite corruption and common crime. On the other hand, in the case of law-and-order policies, criminality has also proved to be a key means by which established political parties have sought to manage this heightened public anger. Xenakis and Cheliotis argue that recognition of the importance of crime in efforts to manage public anger is not only a necessary step for appreciating the direction of politics under crisis and its socio-political ramifications within the Greek context; it is equally a step that enhances and extends our understanding of the relationship between politics and emotions more broadly.

In Chapter 9, Athanasia Chalari focuses on the micro-social level, providing us with an empirical assessment of citizens' subjective experiences of and participation in social change in contemporary Greece. As with the previous chapter, this is a surprisingly under-researched aspect of the Greek case and there are broader lessons regarding crisis management and social change from the perspective of the citizen. Employing interview data, Chalari suggests that practices, norms and mentalities inherited by previous generations are questioned by many. Customs (such as clientelism) and mentalities (such as prioritising the personal over the collective interest) ought to change and be reformed, as the new reality demands different ways of thinking and rapid adaptation to a new way of living, which has become economically restricted and politically unstable. In this sense, it is argued, Greeks are becoming reflexive towards the present situation and about their own role within it, as well as critically engaged with both the past and future, as they consider which parts of the older generations' established mentalities to retain and which aspects of their way of life to alter.

The final, comparative, section of the book begins with Chapter 10, by Dimitris Tsarouhas, who compares Greek and Turkish political responses to economic crises in 2010 and 2001, respectively. The chapter focuses on the reasons some instances of economic crisis lead to a strengthening of reform efforts, while others result in inertia and on the role that discourse and agents play in promoting or obscuring reform under critical circumstances. At structural level, it is argued, although both 
countries went through a critical juncture in the late 1970s and early 1980s, these junctures led to diverse policy outcomes. While Turkey's previous path was transformed towards a fully liberalised political economy regime, the statist path persisted in Greece. When the crisis hit, Greece found itself paralysed and basic political economy reforms were put on hold for years. In Turkey, the 2001 crisis acted as a catalyst for change and the country found itself on sound economic ground within a short space of time. Examining the empirical record by use of a discursive institutionalist approach, this chapter argues that communicating the crisis and coordinating the political response to it are crucial determinants of policy outcomes. It also underlines the positive or negative role that influential policy entrepreneurs can play in that process.

In their contribution, Sebastian Dellepiane-Avellaneda and Niamh Hardiman explore politics of fiscal efforts in Ireland and Spain (Chapter 11). The chapter's core argument is that although the scale of fiscal adjustment that has been expected of Greece is more severe than that seen in any other eurozone member state, the politics of austerity are problematic in very similar ways. Firstly, attempts at closing the fiscal gap require difficult choices about distributive outcomes, whether in the form of increased taxes or reduced expenditure, which need to be better understood. Secondly, since the success of fiscal adjustment is measured with reference to GDP figures that are themselves fluid, these policies are tracking a moving target. In these circumstances, it is likely that the expected credibility gains, especially with ratings agencies, may prove highly elusive, calling into question not only the attainability but the very purpose of the austerity measures. Thirdly, even if it may be true that austerity, pursued long enough, will eventually result in reducing the deficit and ultimately also the debt, this cannot be treated only as a technical exercise in economics. In democratic societies, governments depend on popular support, and this may erode faster than the austerity programme requires. These three themes are explored with reference to the fiscal adjustment strategies adopted by Ireland and Spain since 2008.

The Argentine crisis of 2001-02, which stands out as a seminal example of extreme austerity, is the focus of Chapter 12 by Sebastian Dellepiane-Avellaneda. At the turn of the millennium, Argentina made a speedy transition from poster child to basket case. In December 2001, following a series of desperate attempts to save a seemingly broken economic model, Argentina's experiment with convertibility and neoliberal reforms ended in tragedy: banking crisis, disorderly debt default, 
widespread social unrest, almost political breakdown. A renewed interest in the Argentine case emerged in the wake of the financial meltdown of 2008, mainly in the form of 'lessons from Argentina to Greece'. However, more often than not, commentators, from both the right and left of the political spectrum, have tended to use Argentina to sell competing narratives of the crisis, largely based on their ideological predispositions and policy preferences. This chapter seeks to provide a more analytical and nuanced account of the politics of austerity and crisis management before, during and after the Argentine collapse of 2001, highlighting the highly political nature of the process of restoring market confidence. Dellepiane-Avellaneda finds that it is not only about pleasing financial markets by sanctioning tough austerity measures; it is also fundamentally about constructing and sustaining electoral and distributional coalitions, while key elites battle to impose a dominant discourse regarding the causes and policy solutions to the crisis.

In Chapter 13, George Papandreou, Prime Minister of Greece between October 2009 and November 2011, provides his own perspective on various aspects of the crisis in Greece and Europe, including the rationale behind his government's decisions and actions. It is based on a conversation with the editors, which took place in Brussels on 4 April 2014, which loosely follows the four-part structure of the book, covering aspects relevant to the framing, policies, politics and comparative implications of economic crisis management and extreme austerity. From the unique position of leading the country during the worst economic crisis of its modern history, Papandreou addresses some of the book's recurring issues and themes, as well as responds to questions and criticisms put forward by other book contributors. Papandreou's chapter sheds light on the complex factors and pressures that affect decision-making processes at the domestic, European and global levels - showing how increasingly interdependent these domains are.

In the concluding chapter 14, we revisit and reflect on the key themes discussed in the book, pull together the strands and lessons that recur throughout the volume, and explore the broader implications of the Greek crisis, for Greece, the European Union and austerity politics in general. We argue that the morally charged and stereotypical framing of the key players both in Europe and within Greece drew attention away from substantive debates and hampered a decision-making process, which was already highly problematic, rushed and inadequate. While Greece avoided the catastrophe of a disorderly default, bank run or Grexit, and now seems to be on a path of recovery, multiple communication and 
policy failures at all levels of political action had, and are still having, a profound impact on the everyday lives of millions of people, as well as on the political system as a whole. Importantly, these developments in Greece appear to be indications of - and provide us with valuable lessons on - much broader structural tensions within the architecture of both European and global governance structures. 